\title{
Parametric Study and Multi-Criteria Optimization in Laser Cladding by a High Power Direct Diode Laser
}

\author{
Parisa Farahmand • Radovan Kovacevic
}

Accepted: 5 September 2014 / Published online: 11 October 2014

(C) Springer Science+Business Media New York 2014

\begin{abstract}
In laser cladding, the performance of the deposited layers subjected to severe working conditions (e.g., wear and high temperature conditions) depends on the mechanical properties, the metallurgical bond to the substrate, and the percentage of dilution. The clad geometry and mechanical characteristics of the deposited layer are influenced greatly by the type of laser used as a heat source and process parameters used. Nowadays, the quality of fabricated coating by laser cladding and the efficiency of this process has improved thanks to the development of high-power diode lasers, with power up to $10 \mathrm{~kW}$. In this study, the laser cladding by a high power direct diode laser (HPDDL) as a new heat source in laser cladding was investigated in detail. The high alloy tool steel material (AISI H13) as feedstock was deposited on mild steel (ASTM A36) by a HPDDL up to 8kW laser and with new design lateral feeding nozzle. The influences of the main process parameters (laser power, powder flow rate, and scanning speed) on the clad-bead geometry (specifically layer height and depth of the heat affected zone), and clad microhardness were studied. Multiple regression analysis was used to develop the analytical models for desired output properties according to input process parameters. The Analysis of Variance was applied to check the accuracy of the developed models. The response surface methodology (RSM) and desirability function were used for multi-criteria optimization of the cladding process. In order to investigate the effect of process parameters on the molten pool evolution, in-situ monitoring was utilized. Finally, the validation results for optimized process conditions show the predicted results were in a good agreement with measured values. The multicriteria optimization makes it possible to acquire an efficient process for a combination of clad geometrical and mechanical characteristics control.
\end{abstract}

Keywords Laser cladding $\cdot$ High power direct diode laser $\cdot$ Response surface methodology $(\mathrm{RSM}) \cdot$ Multi-response optimization

P. Farahmand $\cdot$ R. Kovacevic $(\bowtie)$

Center for Laser-aided Manufacturing, Lyle School of Engineering, Southern Methodist University, 3101

Dyer Street, Dallas, TX 75205, USA

e-mail: kovacevi@lyle.smu.edu 


\section{Introduction}

Laser cladding (LC) is a promising surface modification technology to deposit coating layers with superior properties, homogenous metallurgical bond, and low dilution into the substrate. This technique enables the fabrication of ferrous and nonferrous tools or parts in low-volume, eliminating the fabrication stages and reducing the production costs $[1,2]$. The most prominent applications of the LC are surface modification, repairing worn-out components, and rapid manufacturing [3]. The use of $\mathrm{CO}_{2}$ laser as the heat source in cladding process has been investigated for many years. Despite the superior properties of clads by this type of laser, the main drawbacks are a small spot size, non-uniform laser distribution, and low laser absorption [4]. However, over the past few years, the advent of high power direct diode laser offers a number of advantages to laser cladding. This kind of laser is characterized by a wider beam spot, shorter wavelength, and uniform laser distribution which leads to have fewer cladding track, lower operational cost, higher laser absorption, and improved coating quality (i.e., fewer cracks and porosity). The higher electrical to optical efficiency and lower capital cost are other economic advantages of direct diode lasers [5]. One of the intrinsic HPDDL properties is the rectangular beam shape with a uniform input power density (top hat). This property allows deposition of a coating layer with a complete metallurgical bond, low dilution, and low porosity. The beam shape of HPDDL can be tailored to a variety of industrial applications and is ideal for processing large surface area parts with localized and minimal heat input.

The operating cycle of the fabricated coating by laser cladding is strongly dependent on the coating quality (e.g., no irregularities, dimensional accuracy, surface quality, good bond, and low dilution), and its mechanical and metallurgical properties [6]. During the cladding process, the main effective input parameters could be categorized as the following: 1) laser characteristics, 2) motion control (i.e., relative velocity), 3) characteristics of powder feeding, and 4) ambient properties [7, 8]. In addition, there are a multitude of physical interactions between the processing parameters making LC a complex process. Laser attenuation by powder, molten pool dynamics, and gas/melt pool interaction are the main effective interactions in the LC process [9, 10]. Small changes in any of the input parameters would result in quality variations. As a result, the designation and proper control of input parameters for obtaining the desired coating quality are very challenging [9].

A number of studies have investigated the effects of process variables and the interaction between them on the quality characteristics of the clad by different types of lasers (fiber, $\mathrm{CO}_{2}$, and $\mathrm{Nd}$ : YAG) lasers as heat source. Oliveira et al. [1] developed empirical relations between process variables and the geometrical characteristics of a single-track Ni-based coating with a Nd: YAG laser. They presented a practical processing window to produce the defect free coating with low dilution to the substrate. Pinkertoon et al. [11] evaluated the optimal condition for repairing components with H13 by a laser metal direct deposition process. They utilized statistical techniques to produce a defect-free coating with the desired microhardness. According to their experimental evidences, an increase in the laser power and powder flow rate tends to minimize the porosity at the boundaries between the original parts and the added material. Choi and Chang [9] utilized statistical techniques to propose the empirical relations for deposited layer thickness, microhardness, and porosity for the direct laser 
deposition of $\mathrm{H} 13$ by a $\mathrm{CO}_{2}$ laser. Their statistical results showed that the powder flow rate has a significant effect on clad height and subsequent pore formation. They concluded that in a multi-layer laser deposition, the optimized overlap percentage and powder flow rate reduced the possibility of inter-lock pore formation. Syed. W et al. [12] investigated multilayer laser cladding of AISI 316 performed by a high power fiber coupled diode laser. They analyzed the composition, microstructure, dimensions, and surface properties of the deposits based on the powder flow rate and scanning speed. They showed that the probability of the crack formation decreases by increasing the powder flow rate; however, it affects the surface roughness. Balu et al. [13] optimized the process parameters in the multi-layered laser cladding of Hastelloy C-276 on mild steel by a fiber laser with RSM. Their study showed a defect free and uniform layer thickness with a fine equiaxed microstructure could be obtained by optimized condition. S. Mondal et al. [14] investigated the optimization of multi performance characteristics of laser cladding by $\mathrm{CO}_{2}$ laser using Taguchi's quality loss function. They developed the interrelationship between process variables and quality responses by using an artificial neural network (ANN). RSM could be coupled also by other optimization algorithms, as an example S. Elangovan et al. [15] determined the optimized conditions in ultrasonic metal welding by coupling RSM with genetic algorithm (GA). They interfaced the developed responses with RSM by GA to find optimum conditions.

The high power direct diode laser is relatively new laser which required accurately control of the coating characteristics, the influence of individual processing parameters as well as their interactions on cladding properties. In this study, laser cladding process with a high power direct diode laser (HPDDL) equipped with a lateral feeding nozzle designed by Coherent, Inc. was studied. The high alloy tool steel (AISI H13) as feedstock material deposited on mild steel A36 due to high demand of die and mold industries. The statistical techniques including Central Composite Design (CCD) design of experiments and Response Surface Methodology (RSM) were used for the multi-objective optimization of the cladding process of AISI H13 that will enhance the cladding characteristics and savings on the cladding time and raw material. The relationship between process parameters and output responses as well as the interaction among the process parameters were analyzed and discussed in detail by Analysis of Variance (ANOVA).

\section{Experimental Procedure}

\section{Materials and Methods}

In this study, the experiments were performed by an $8 \mathrm{~kW}, 975 \mathrm{~nm}$ wavelength direct diode laser and a 6-axis KUKA robot. The experimental setup also includes laser power supply with a control unit and laser splitting controller, as well as a chiller for the laser head and cladding nozzles during the process. A high-speed CCD camera assisted by a green laser (532 nm wave length) was utilized for capturing the molten pool evolution. Figure 1 shows the experimental set up and schematic view of the cladding process and in-situ monitoring. 


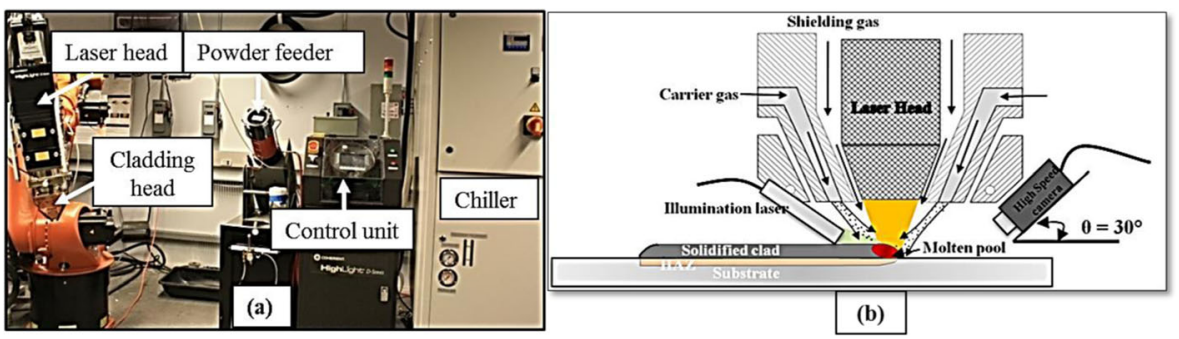

Fig. 1 a Experimental set up b schematic view of laser cladding by HPDDL

The powder was transported through two symmetric co-axial nozzles with seven $1 \mathrm{~mm}$ square channels. This lateral powder delivery apparatus were especially designed for laser cladding by Coherent Inc. [16]. Fig. 2 shows the powder delivery system used in this study. Argon was used as both the carrier gas as well as the shielding gas to protect the molten pool from oxidation.

The substrate material was mild steel (ASTM A36) and the cladding powder was AISI H13. The hardness and chemical composition of the substrate is and the powder characteristics, and chemical composition of H13 are listed in Table 1 . Also, the fixed processing factors in the laser cladding process are listed in Table 2 .

\section{Measurements}

The geometrical features of cross-sections were studied by an optical microscope. The characteristics of microstructure and composition of deposited material were also investigated by a scanning electron microscope (SEM) and Energy Dispersive Spectroscopy (EDS), respectively. The microhardness values were obtained by using a load of $500 \mathrm{gf}$ with a dwell time $15 \mathrm{~s}$ in a digital microhardness tester. For each sample, the microhardness represents an average of measurements taken along the clad height with $0.3 \mathrm{~mm}$ increments and clad width by $1.5 \mathrm{~mm}$ increments. Figure 4 shows the schematic view of the

(a)

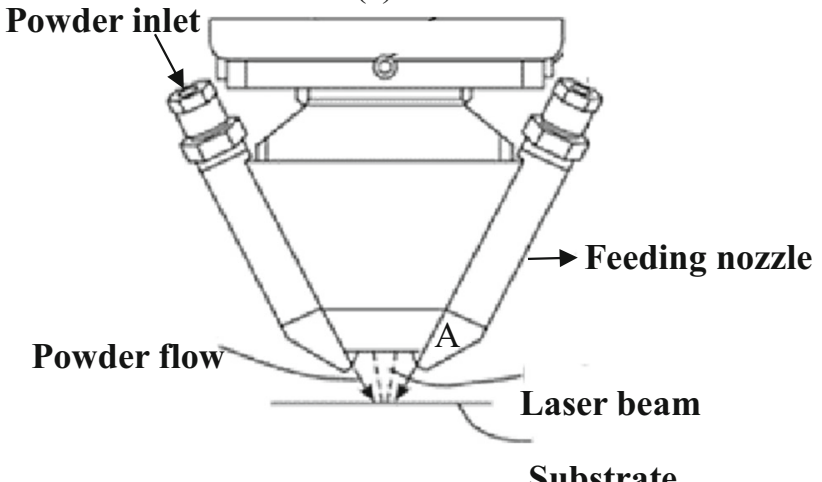

(b)

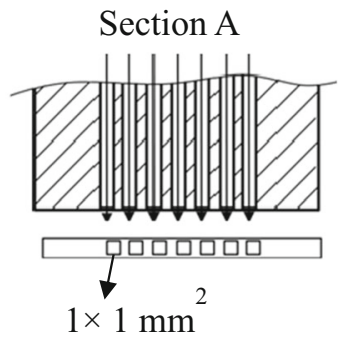

Fig. 2 Configuration of the powder-delivery apparatus, b) feeding channels [16] 
Table 1 Characteristics and chemical composition of H13 powder and ASTM A36 substrate

\begin{tabular}{|c|c|c|c|c|}
\hline Steel & Melting Point $\left({ }^{\circ} \mathrm{C}\right)$ & Type of particle & Particle size range & Chemical composition $(\%)$ \\
\hline AISI H13 & 1,480 & Spherical & $-80+325$ Mesh & $\begin{array}{l}0.4 \mathrm{C} ; 1 \mathrm{Si} ; 0.3 \mathrm{Mn} ; 5.3 \mathrm{Cr} \\
1.4 \text { months; } 1 \mathrm{~V} ; \mathrm{Bal} . \mathrm{Fe}\end{array}$ \\
\hline ASTM A36 & 1,370 & - & - & $\begin{array}{l}0.23 \mathrm{C} ; 0.02 \mathrm{Si} ; 0.49 \mathrm{Mn} ; 0.01 \mathrm{~S} ; \\
\quad 0.01 \mathrm{P} ; 0.01 \mathrm{Ni} ; 0.03 \mathrm{Cu} ; \mathrm{Bal} . \mathrm{Fe}\end{array}$ \\
\hline
\end{tabular}

selected output responses for optimization. The clad height, HAZ depth, and coating microhardness were the selected output responses. One of intrinsic properties of HPDDL is a uniform laser power distribution "top hat". This uniform distribution causes to have a very narrow intermixing zone between clad layer and substrate. Figure 3 compares the cross section of clad by a fiber laser and HPDDL.

Since the dilution depth in laser cladded track with high power diode laser is very shallow, less than $10 \mu \mathrm{m}$ (see Fig. 4b) and it could not be measured by optical microscope; therefore, the HAZ depth (marked D in Fig. 4a) was selected as an output response.

\section{Design of Experiments}

The experiments were performed according to second order central composite rotatable design. This method of experimental design is the most efficient design matrix for Response Surface Methodology (RSM) application. Central composite design offers the least possible number of experiments without losing its accuracy [17]. A three-factor with four-level central composite design with 20 experimental trials were established. The process parameters with their values and corresponding levels are listed in Table 3 .

In the central composite design, $\alpha$ value was selected as 2 because in this type of experimental design, $\alpha$ factor plays a crucial role. This value should be large enough to ensure that there is a large enough investigation space for all level sets which can clearly detect the effect of individual factors.

Table 2 Fixed processing parameters in the cladding process

Fixed parameters

$\begin{array}{ll}\text { Laser beam diameter at substrate } & 12 \mathrm{~mm} \times 3 \mathrm{~mm} \\ \text { Distance, nozzle-substrate } & 8 \mathrm{~mm} \\ \text { Shielding gas } & \text { Argon (Ar) } \\ \text { Powder transport gas } & \text { Argon (Ar) } \\ \text { Shielding gas pressure } & 40 \text { bar } \\ \text { Flow powder transport gas } & 15 \mathrm{CFH}\end{array}$


(a)

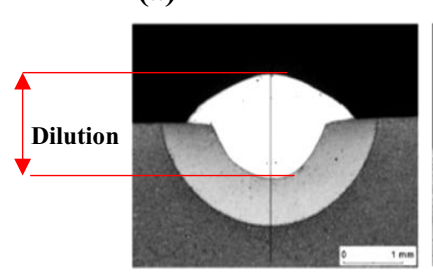

(c)

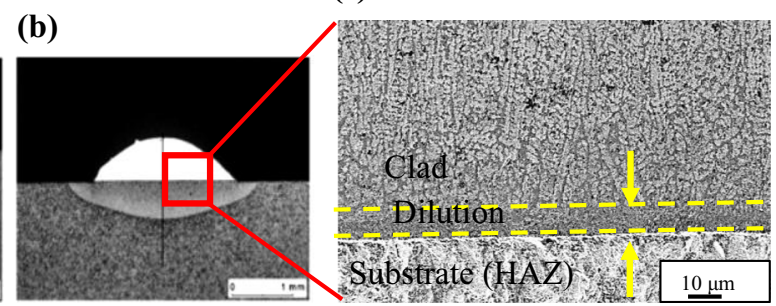

(b)

Fig. 3 a cross section of laser clad by a fiber laser, b cross section of laser clad by an HPDDL, c SEM image of interface zone of HPDDL cladded surface

\section{Result and Discussion}

The single-track laser cladding based on CCD matrix design with defined levels for input variables was performed with 20 sets of process parameters. Table 4 represents the final DOE matrix with coded levels and actual values of the input parameters and their corresponding average measured responses.

\section{Multiple Regression Design}

In a typical multi-input, multi-response experimental procedure, multiple regression design is a common method to model a response as a mathematical function (i.e., empirical model) of a few continuous factors. In the regression method, a comprehensive model that covers all possible main and interaction effects is desired [17]. For single-track laser cladding with several interactions among main input variables, the best choice is the second-order polynomial model; expressed by Eq. 1:

$$
Y=f(x)=\alpha_{0}+\sum_{i=1}^{K} \alpha_{i} X_{i}+\sum_{i=1}^{k} \sum_{j=i+1}^{k} \alpha_{i j} X_{i} X_{j}+\sum_{i=1}^{k} \alpha_{i i} X_{i}^{2}+e_{r}
$$

where $\mathbf{k}$ is the number of independent variables (factors), $\mathbf{x}_{\mathbf{i}}(\mathrm{i}=1,2,3)$ are input predictors or controlling variables, $\alpha_{\mathbf{0}}$ is constant coefficient, $\boldsymbol{\alpha}_{\mathbf{i}}, \boldsymbol{\alpha}_{\mathbf{i j}}$ and $\boldsymbol{\alpha}_{\mathbf{i i}}$ are coefficients of linear, interaction and quadratic terms, respectively. To correlate the interest responses of single-track clads, the responses $\mathbf{Y}$, clad height, HAZ depth, and mean microhardness of the clad layer could be defined as functions of laser power

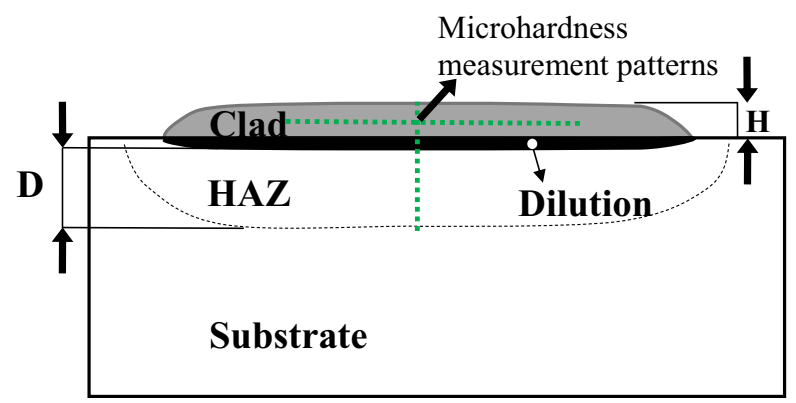

Fig. 4 a Schematic view of selected responses of laser clad, b SEM image of clad at interface with substrate 
Table 3 Input variables and their design levels

\begin{tabular}{llllllll}
\hline \multirow{2}{*}{ parameters } & \multicolumn{7}{c}{ Levels of parameters } \\
\cline { 4 - 7 } & Notation & Unit & $-2(-\alpha)$ & -1 & 0 & 1 & $2(+\alpha)$ \\
\hline Laser Power & LP & Watts & 3,500 & 3,650 & 3,800 & 3,950 & 4,100 \\
Scanning Speed & SS & $\mathrm{mm} / \mathrm{s}$ & 3 & 4 & 5 & 6 & 7 \\
Powder flow rate & PFR & $\mathrm{g} / \mathrm{s}$ & 0.6 & 0.675 & 0.75 & 0.825 & 0.9 \\
\hline
\end{tabular}

(LP), scanning speed (SS), and powder flow rate (PFR). Then, the polynomial equation for the responses is (Eq. 3.3):

$$
\begin{aligned}
\mathrm{Y} & =\alpha_{0}+\alpha_{1}(\mathrm{LP})+\alpha_{2}(\mathrm{SS})+\alpha_{3}(\mathrm{PFR})+\alpha_{12}(\mathrm{LP} . \mathrm{SS}) \\
& +\alpha_{13}(\mathrm{LP} . \mathrm{PFR})+\alpha_{23}(\mathrm{SS} . \mathrm{PFR})+\alpha_{11}\left(\mathrm{LP}^{2}\right)+\alpha_{22}\left(\mathrm{SS}^{2}\right)+\alpha_{33}\left(\mathrm{PFR}^{2}\right)+\mathrm{e}_{\mathrm{r}}
\end{aligned}
$$

\begin{tabular}{|c|c|c|c|c|c|c|c|c|c|}
\hline \multirow{3}{*}{$\begin{array}{l}\text { Exp. } \\
\text { No. }\end{array}$} & \multicolumn{3}{|c|}{ Coded values } & \multicolumn{6}{|c|}{ Responses } \\
\hline & \multirow[t]{2}{*}{ LP } & \multirow[t]{2}{*}{ SS } & \multirow[t]{2}{*}{ PFR } & \multicolumn{2}{|c|}{ Clad Height (mm) } & \multicolumn{2}{|c|}{ HAZ depth (mm) } & \multicolumn{2}{|c|}{$\begin{array}{l}\text { Mean Micro hardness } \\
(\mathrm{HV})\end{array}$} \\
\hline & & & & $\begin{array}{l}\text { Mean } \\
\text { value }\end{array}$ & $\begin{array}{l}\text { Standard } \\
\text { deviation }\end{array}$ & $\begin{array}{l}\text { Mean } \\
\text { value }\end{array}$ & $\begin{array}{l}\text { Standard } \\
\text { deviation }\end{array}$ & $\begin{array}{l}\text { Mean } \\
\text { value }\end{array}$ & $\begin{array}{l}\text { Standard } \\
\text { deviation }\end{array}$ \\
\hline 1 & -1 & -1 & -1 & 1.14 & \pm 0.006 & 1.98 & \pm 0.002 & 645 & \pm 11 \\
\hline 2 & 1 & -1 & -1 & 1.19 & \pm 0.004 & 2.19 & \pm 0.006 & 643.5 & \pm 18 \\
\hline 3 & -1 & 1 & -1 & 0.8 & \pm 0.008 & 1.55 & \pm 0.006 & 669 & \pm 19 \\
\hline 4 & 1 & 1 & -1 & 1.02 & \pm 0.01 & 1.78 & \pm 0.009 & 664 & \pm 10 \\
\hline 5 & -1 & -1 & 1 & 1.49 & \pm 0.003 & 1.89 & \pm 0.004 & 647.3 & \pm 12 \\
\hline 6 & 1 & -1 & 1 & 1.5 & \pm 0.006 & 2.04 & \pm 0.006 & 643 & \pm 8 \\
\hline 7 & -1 & 1 & 1 & 0.98 & \pm 0.003 & 1.28 & \pm 0.005 & 658 & \pm 15 \\
\hline 8 & 1 & 1 & 1 & 1.28 & \pm 0.009 & 1.45 & \pm 0.007 & 668 & \pm 25 \\
\hline 9 & -2 & 0 & 0 & 1.03 & \pm 0.01 & 1.64 & \pm 0.006 & 668 & \pm 18 \\
\hline 10 & 2 & 0 & 0 & 1.52 & \pm 0.003 & 1.92 & \pm 0.002 & 642 & \pm 16 \\
\hline 11 & 0 & -2 & 0 & 1.32 & \pm 0.005 & 1.74 & \pm 0.008 & 638 & \pm 13 \\
\hline 12 & 0 & 2 & 0 & 0.89 & \pm 0.002 & 1.53 & \pm 0.01 & 678 & \pm 22 \\
\hline 13 & 0 & 0 & -2 & 1.26 & \pm 0.01 & 1.65 & \pm 0.003 & 645 & \pm 7 \\
\hline 14 & 0 & 0 & 2 & 1.44 & \pm 0.006 & 1.36 & \pm 0.005 & 660 & \pm 21 \\
\hline 15 & 0 & 0 & 0 & 1.11 & \pm 0.009 & 1.45 & \pm 0.007 & 665 & \pm 14 \\
\hline 16 & 0 & 0 & 0 & 1.18 & \pm 0.006 & 1.39 & \pm 0.006 & 662 & \pm 16 \\
\hline 17 & 0 & 0 & 0 & 1.16 & \pm 0.007 & 1.48 & \pm 0.008 & 662 & \pm 13 \\
\hline 18 & 0 & 0 & 0 & 1.07 & \pm 0.009 & 1.23 & \pm 0.007 & 663 & \pm 14 \\
\hline 19 & 0 & 0 & 0 & 1.18 & \pm 0.005 & 1.39 & \pm 0.005 & 660.4 & \pm 15 \\
\hline 20 & 0 & 0 & 0 & 1.11 & \pm 0.007 & 1.41 & \pm 0.008 & 661 & \pm 16 \\
\hline
\end{tabular}

Table 4 Central composite design matrix and corresponding experimental responses 
The parameter coefficients and empirical model for each response based on multiple linear regression analysis with RSM were established in Design Expert Software V.7.0.

\section{ANOVA Analysis and Development of Response Surface (RS) Regression Model}

In order to develop RS model based on Eq. 2, an Analysis of Variance (ANOVA) technique was used to locate the significant effective input parameters and interactions among them on specific response. The stepwise regression method in ANOVA analysis was used to eliminate the insignificant terms. This technique compares the probability value of each term of analytical model with a Fisher ratio at the certain level of confidence. In ANOVA analysis each term would be significant if the $p$-value (significant probability value) is less than confidence level [18]. In this study, the level of confidence for developed model is considered to be $95 \%$. Therefore, the values of " $p$-value" less than 0.05 indicate the terms had a significant effect in the empirical relationships. The ANOVA test results for clad height, HAZ depth, and microhardness are shown in Tables 5, 6, and 7, respectively.

The significant effective input parameters for each response are listed In ANOVA analyses tables. The $\mathrm{R}^{2}$ value is used to check the fit between predicted and measured data. For all the output responses, the $\mathrm{R}^{2}$ value was close to one that showed the high correlation between experimental and predicted results. Based on ANOVA analysis, the interaction of laser power and scanning speed for clad height, the interaction of laser power and powder flow rate for HAZ depth, and the interaction of laser power and scanning speed for microhardness were the most significant interactions associated to the

Table 5 ANOVA analysis for clad height

\begin{tabular}{|c|c|c|c|c|c|c|}
\hline Source & $\begin{array}{l}\text { Sums of } \\
\text { Squares }\end{array}$ & $\mathrm{DF}$ & Mean Square & F Value & $p$-value & Significant \\
\hline Model & 0.68 & 6 & 0.11 & 18.35 & $<0.0001$ & Yes \\
\hline LP & 0.16 & 1 & 0.16 & 26.64 & 0.0002 & Yes \\
\hline SS & 0.26 & 1 & 0.26 & 42.14 & $<0.0001$ & Yes \\
\hline PFR & 0.14 & 1 & 0.14 & 22.57 & 0.0004 & Yes \\
\hline LP*SS & 0.034 & 1 & 0.034 & 5.50 & 0.0356 & Yes \\
\hline $\mathrm{LP}^{2}$ & 0.031 & 1 & 0.031 & 5.00 & 0.0436 & Yes \\
\hline $\mathrm{PFR}^{2}$ & 0.074 & 1 & 0.074 & 11.94 & 0.0043 & Yes \\
\hline Residual & 0.080 & 13 & $6.158 \mathrm{E}-003$ & & & \\
\hline Lack of Fit & 0.070 & 8 & $8.739 \mathrm{E}-003$ & 4.30 & 0.0623 & No \\
\hline Pure Error & 0.010 & 5 & $2.030 \mathrm{E}-003$ & & & \\
\hline \multirow[t]{4}{*}{ Core Total } & 0.76 & 19 & & $\mathrm{R}^{2}$ & 0.9633 & \\
\hline & & & & Adjusted $\mathrm{R}^{2}$ & 0.8852 & \\
\hline & & & & Predicted $\mathrm{R}^{2}$ & 0.895 & \\
\hline & & & & Adequate Precision & 22.492 & \\
\hline
\end{tabular}


Table 6 ANOVA analysis for HAZ depth

\begin{tabular}{|c|c|c|c|c|c|c|}
\hline Source & $\begin{array}{l}\text { Sums of } \\
\text { Squares }\end{array}$ & $\mathrm{DF}$ & Mean Square & F Value & Prob $>F$ & Significant \\
\hline Model & 1.37 & 8 & 0.11 & 16.77 & 0.0012 & Yes \\
\hline LP & 0.029 & 1 & 0.029 & 4.57 & $<0.0001$ & Yes \\
\hline SS & 0.001 & 1 & 0.001 & 0.19 & 0.001 & Yes \\
\hline PFR & 0.042 & 1 & 0.042 & 6.68 & 0.0415 & Yes \\
\hline LP*PFR & 0.001 & 1 & 0.001 & 0.26 & 0.003 & Yes \\
\hline $\mathrm{LP}^{2}$ & 0.23 & 1 & 0.23 & 35.92 & 0.0010 & Yes \\
\hline $\mathrm{SS}^{2}$ & 0.089 & 1 & 0.089 & 14.10 & 0.0094 & Yes \\
\hline Residual & 0.17 & 10 & 0.017 & & & \\
\hline Lack of Fit & 0.0017 & 5 & 0.0017 & 0.46 & 0.82 & No \\
\hline Pure Error & 0.001 & 5 & 0.0002 & & & \\
\hline \multirow[t]{4}{*}{ Core Total } & 0.135 & 19 & & $\mathrm{R}^{2}$ & 0.9757 & \\
\hline & & & & Adjusted $\mathrm{R}^{2}$ & 0.9637 & \\
\hline & & & & Predicted $\mathrm{R}^{2}$ & 0.9721 & \\
\hline & & & & Adequate Precision & 15.02 & \\
\hline
\end{tabular}

selected responses. Suitable response models based on fit summaries were established. Based on developed models, it is evident that all responses were affected by two-factor interactions.

$$
\begin{aligned}
\text { CladHeigth } & =33.72-0.013 \times L P-1.77 \times S S-12.83 \times P F R \\
& +0.04 \times(L P \times S S)+0.001 \times(L P)^{2}+9.47 \times(P F R)^{2}
\end{aligned}
$$

\begin{tabular}{|c|c|c|c|c|c|c|}
\hline Source & $\begin{array}{l}\text { Sums of } \\
\text { Squares }\end{array}$ & $\mathrm{DF}$ & Mean Square & $\mathrm{F}$ Value & Prob $>F$ & Significant \\
\hline Model & 2065.85 & 9 & 229.54 & 6.68 & 0.0033 & Yes \\
\hline LP & 891.17 & 1 & 891.17 & 24.22 & 0.0037 & Yes \\
\hline SS & $1,592.45$ & 1 & $1,592.45$ & 46.32 & $<0.0001$ & Yes \\
\hline LP*SS & 145.8 & 1 & 145.8 & 12.42 & 0.0028 & Yes \\
\hline $\mathrm{LP}^{2}$ & 194.45 & 1 & 194.45 & 12.75 & 0.0028 & Yes \\
\hline $\mathrm{SS}^{2}$ & 170.93 & 1 & 170.93 & 14.97 & 0.0016 & Yes \\
\hline Residual & 343.81 & 10 & 34.38 & & & \\
\hline Lack of Fit & 330.57 & 5 & 66.11 & 0.245 & 0.4453 & No \\
\hline Pure Error & 13.23 & 5 & 2.65 & & & \\
\hline \multirow[t]{4}{*}{ Core Total } & $2,409.66$ & 19 & & $\mathrm{R}^{2}$ & 0.9573 & \\
\hline & & & & Adjusted $\mathrm{R}^{2}$ & 0.9289 & \\
\hline & & & & Predicted $\mathrm{R}^{2}$ & 0.9476 & \\
\hline & & & & Adequate Precision & 9.87 & \\
\hline
\end{tabular}

Table 7 ANOVA analysis for coating microhardness 


$$
\begin{aligned}
\text { HAZDepth } & =1.39+0.1 \times L P-0.13 \times S S-0.11 \times P F R \\
& +0.047 \times(L P \times P F R)+0.097 \times L P^{2}+0.061 \times S S^{2}
\end{aligned}
$$

$$
\text { Microhardness }=467.57-0.02 \times L P+9.96 \times S S+583.39 \times(L P \times S S)-376 \times P F R^{2}
$$

In Eqs. 3, 4, and 5, the terms with a positive sign have additive effects and the terms with negative sign have subtractive effects on the responses. The developed equations should be checked if the models accurately approximate the responses.

\section{Validation of Developed Models}

Figure 5 shows the relationship between actual and predicted results and normal probability of the developed models vs. residuals. This figure indicates that the developed models were adequate because the residuals tend to follow the diagonal line. Distribution of the residuals along a straight diagonal line indicates that errors are normally distributed and the empirical relationship is correctly developed. Figure 5 further confirms that the predicted results based on developed analytical models were in a good agreement with the actual measured results and then the adequacy of developed models were verified. Furthermore, to validate the adequacy of the developed models, three new confirmation tests were performed within the range defined earlier.

Table 8 summarizes the experimental conditions, the actual and predicted results, and the percentage of the errors. The results indicates that the developed models could predict the responses with less than $5 \%$ error.

\section{The Effect of Process Parameters on Clad Height Based on RSM}

Figure 6 is perturbation plot, which illustrates the effect of all factors at the center point of the design on clad height. A, B, C, symbolize the different process parameters, namely laser power, scanning speed, and powder flow rate, respectively. This figure shows that scanning speed had a linear negative effect on the clad height. Higher scanning speed led to the less injected metal powder onto the molten pool and cladded track would be thinner. Laser power and powder flow rate had a lightly positive effects on the clad height. In this figure, it is clear that the variation of clad height is more pronounced by changing the scanning speed than laser power and powder flow rate. The variation in the clad height for the laser power values before the center point was smaller than when the laser power values were above the center point. This might be attributed to the fact that the laser power under the center point was not high enough to melt all the injected powder and consequently a lower powder catchment efficiency occurred.

As Table 5 shows, among the interactions between input process parameters, the interaction between laser power and scanning speed was the main significant interaction factor on clad height. Figure $7 \mathrm{a}, \mathrm{b}$ show response surfaces and 
(a)

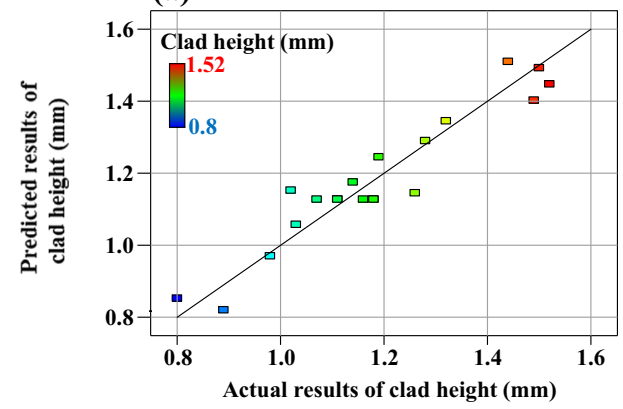

(b)

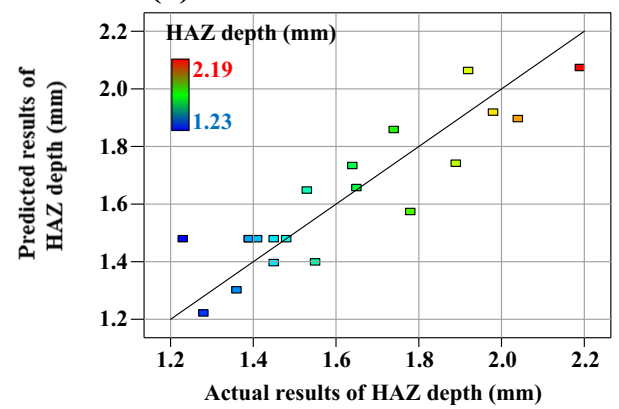

(c)

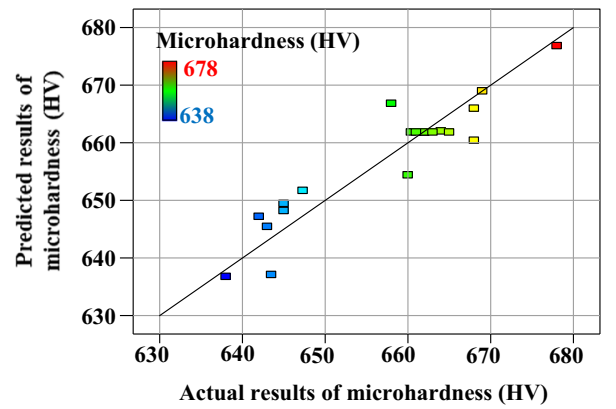

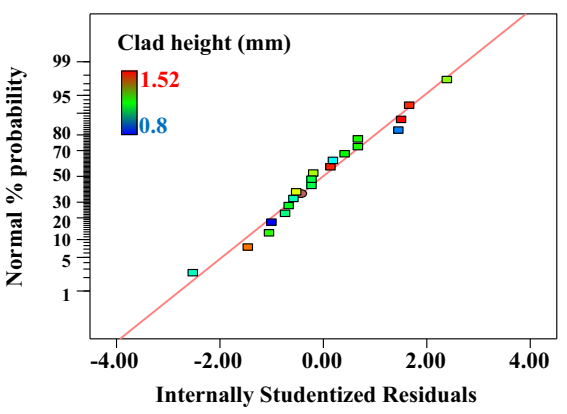
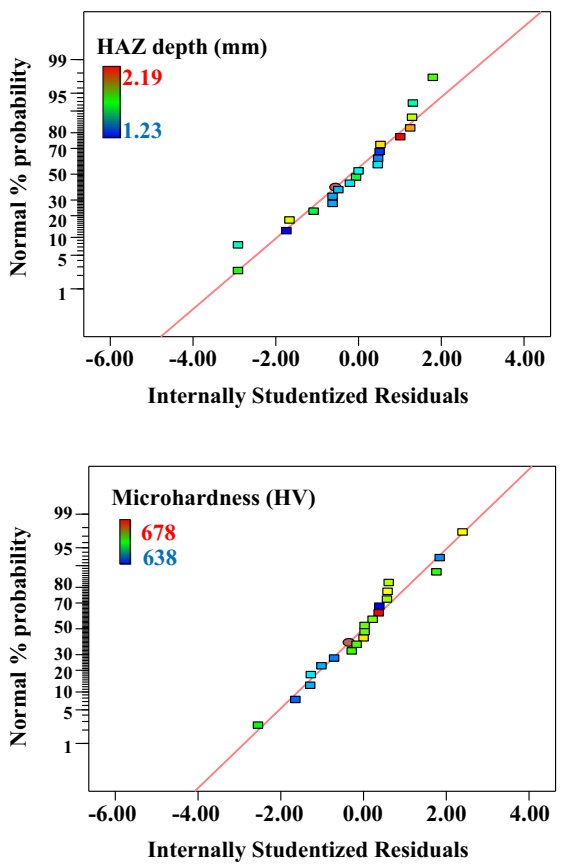

Fig. 5 Normal probability plot of residuals and predicted vs. measured results for a clad height, $\mathbf{b}$ HAZ depth, c coating microhardness

counter graphs of the effect of interaction of laser power and scanning speed on clad height while keeping powder flow rate at zero level. It is observed that by keeping the laser power either at higher or lower level and at the same time decreasing the scanning speed could lead to the maximum clad height. Figure $7 \mathrm{c}, \mathrm{d}$ illustrate the effect of interaction between laser power and powder flow rate on the clad height for the center level of scanning speed. The clad height increased with rising the powder flow rate and increasing the laser power up to the maximum value. The largest clad height could be achieved under the maximum powder flow rate and the maximum laser power. 
Table 8 Confirmation experiments

\begin{tabular}{|c|c|c|c|c|c|c|c|}
\hline Exp. No & $\begin{array}{l}\mathrm{LP} \\
(\mathrm{W})\end{array}$ & $\begin{array}{l}\mathrm{SS} \\
(\mathrm{mm} / \mathrm{s})\end{array}$ & $\begin{array}{l}\text { PFR } \\
(\mathrm{g} / \mathrm{s})\end{array}$ & & $\begin{array}{l}\text { Clad Height } \\
(\mathrm{mm})\end{array}$ & $\begin{array}{l}\text { HAZ Depth } \\
(\mathrm{mm})\end{array}$ & $\begin{array}{l}\text { Microhardness } \\
(\mathrm{HV})\end{array}$ \\
\hline \multirow[t]{3}{*}{ EXP.I } & \multirow[t]{3}{*}{3,650} & \multirow[t]{3}{*}{4} & \multirow[t]{3}{*}{0.675} & Actual & 1.12 & 1.98 & 645 \\
\hline & & & & Predicted & 1.16 & 2.01 & 630 \\
\hline & & & & Error \% & 3.57 & 1.5 & 2.3 \\
\hline \multirow[t]{3}{*}{ EXP.II } & \multirow[t]{3}{*}{3,800} & \multirow[t]{3}{*}{7} & \multirow[t]{3}{*}{0.75} & Actual & 0.89 & 1.53 & 678 \\
\hline & & & & Predicted & 0.93 & 1.48 & 686 \\
\hline & & & & Error \% & 4.49 & 3.2 & 1.1 \\
\hline \multirow[t]{3}{*}{ EXP. III } & \multirow[t]{3}{*}{3,650} & \multirow[t]{3}{*}{6} & \multirow[t]{3}{*}{0.825} & Actual & 0.96 & 1.28 & 658 \\
\hline & & & & Predicted & 1.023 & 1.32 & 688 \\
\hline & & & & Error \% & 4.5 & 3.1 & 4.5 \\
\hline
\end{tabular}

The Effect of Process Parameters on HAZ Depth Based on RSM

Figure 8 shows the perturbation plot of the effect of all selected input factors at the center point in the design space on the HAZ depth. As it is seen both scanning speed and powder flow rate had negative effects on the HAZ depth. It is also shown that the effect of scanning speed was more significant than the effect of powder flow rate. The absorbed laser power density by substrate at the high scanning speed level was low and subsequently, the HAZ depth was shallow. The increase in powder flow rate lead to higher absorption of laser power by the injected metal powder into the molten pool and therefore less heat energy was transferred into the substrate.

When it comes to the laser power, the HAZ depth slightly decreased by increasing the laser power before reaching the center point. This could be attributed to the low level of laser power before the center point which was completely consumed by melting the injected powder. However, the HAZ depth increased by increasing the

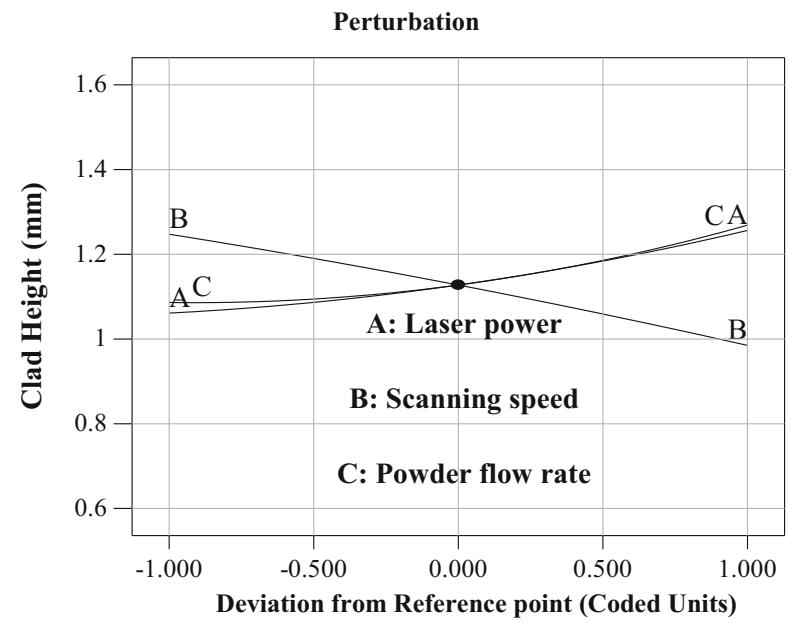

Fig. 6 Perturbation plot showing the effect of all processing parameters on clad height 

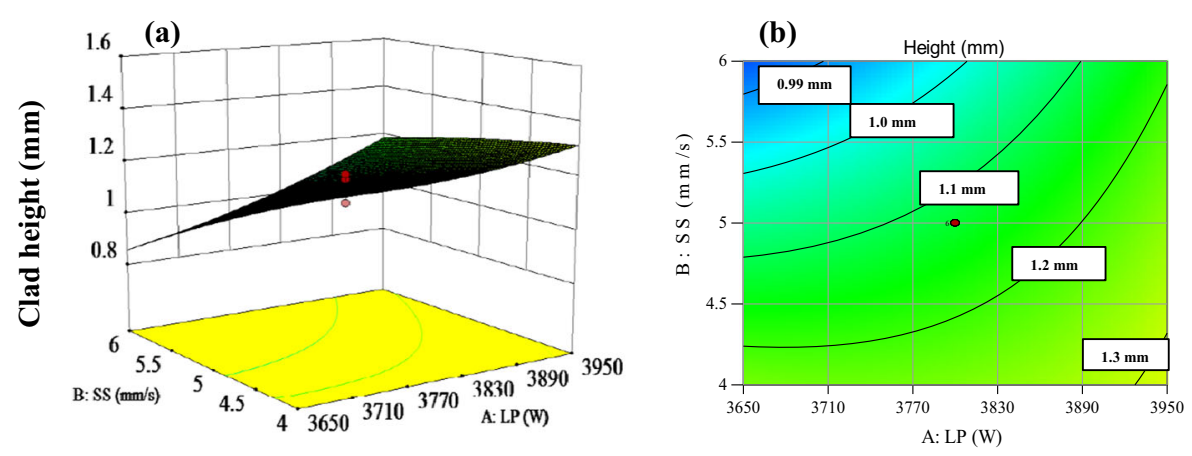

(c)

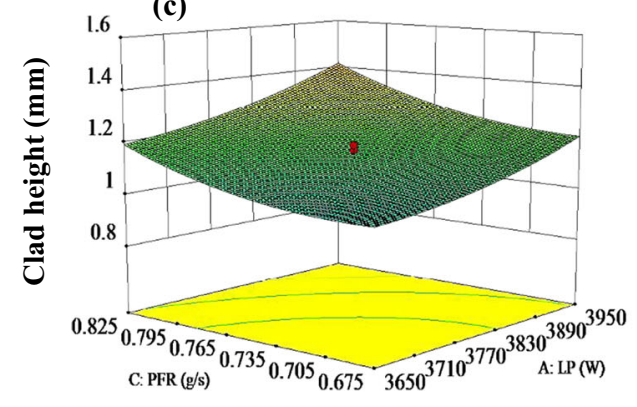

(d)

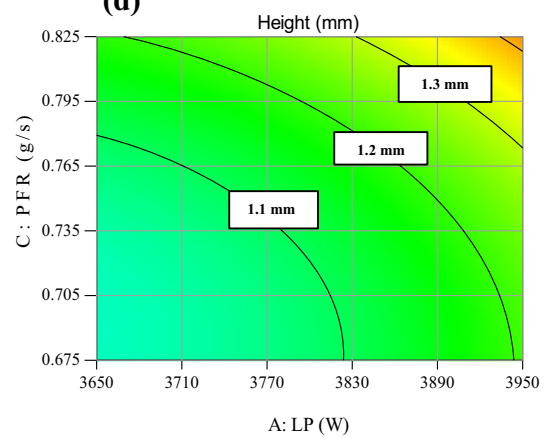

Fig. 7 a 3D surface plot, $\mathbf{b}$ counter graph of interaction effect of laser power and scanning speed on clad height, $\mathbf{c}$ 3D surface plot, $\mathbf{d}$ contour graph of interaction effect of laser power and powder flow rate on clad height

laser power values after the center point. The main interaction effect on the HAZ depth, based on Table 6, was between the laser power and powder flow rate. Figure 9 shows the response surface and graphical contour for the effect of interaction between laser power and scanning speed as well as the laser power and powder flow rate on the HAZ

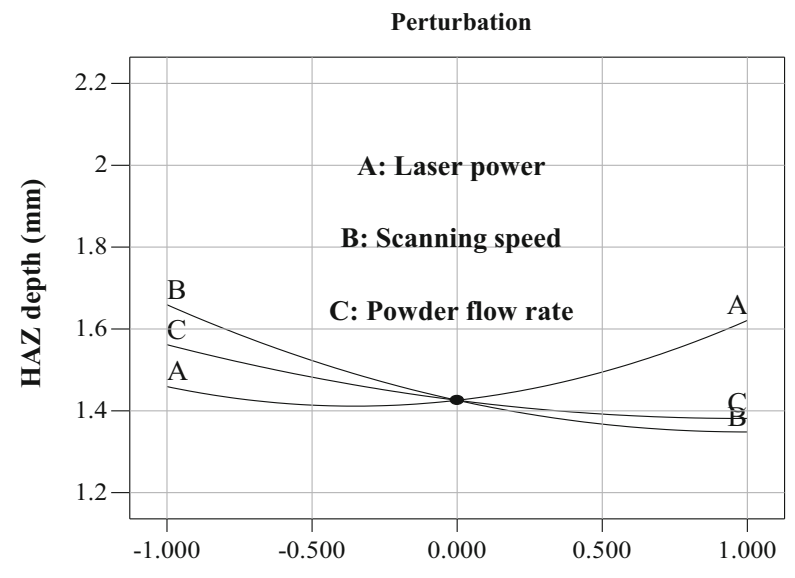

Deviation from Reference Point (Coded Units)

Fig. 8 Perturbation plot showing the effect of all the processing parameters on the depth of HAZ 
depth. Form Fig. 9a, b, it could be seen that for the parameter region close to the center of the response surface, the HAZ depth was shallower. The minimum HAZ depth could be obtain with the values of the processing parameters close to the center of domain. The interaction of the effect of laser power and scanning speed on HAZ depth is shown in Fig. 9c, d. This figures indicate at the highest level of scanning speed, the HAZ would be shallow either with high or low level of laser power.

\section{The Effect of Process Parameters on Microhardness Based on RSM}

The microhardness of the clad layer based on perturbation plot (see Fig. 10) was mainly affected by the scanning speed. By increasing the scanning speed, the cooling rate will rise and consequently the clad layer microhardness will increase [19]. The laser power had the negative effect on the microhardness, by increasing the laser power, the cooling rate decreased, which led to a decrease in the microhardness. The variation in microhardness with the change of powder flow rate was very small.

Table 7 shows that the interaction between laser power and scanning speed among the processing parameters interactions has a significant effect on coating microhardness. Figure 11 shows the surface responses and graphical contours of the interaction between laser power and scanning speed as well as laser power and powder flow rate on the clad microhardness. Figure 11a, b indicate that by keeping the scanning speed at
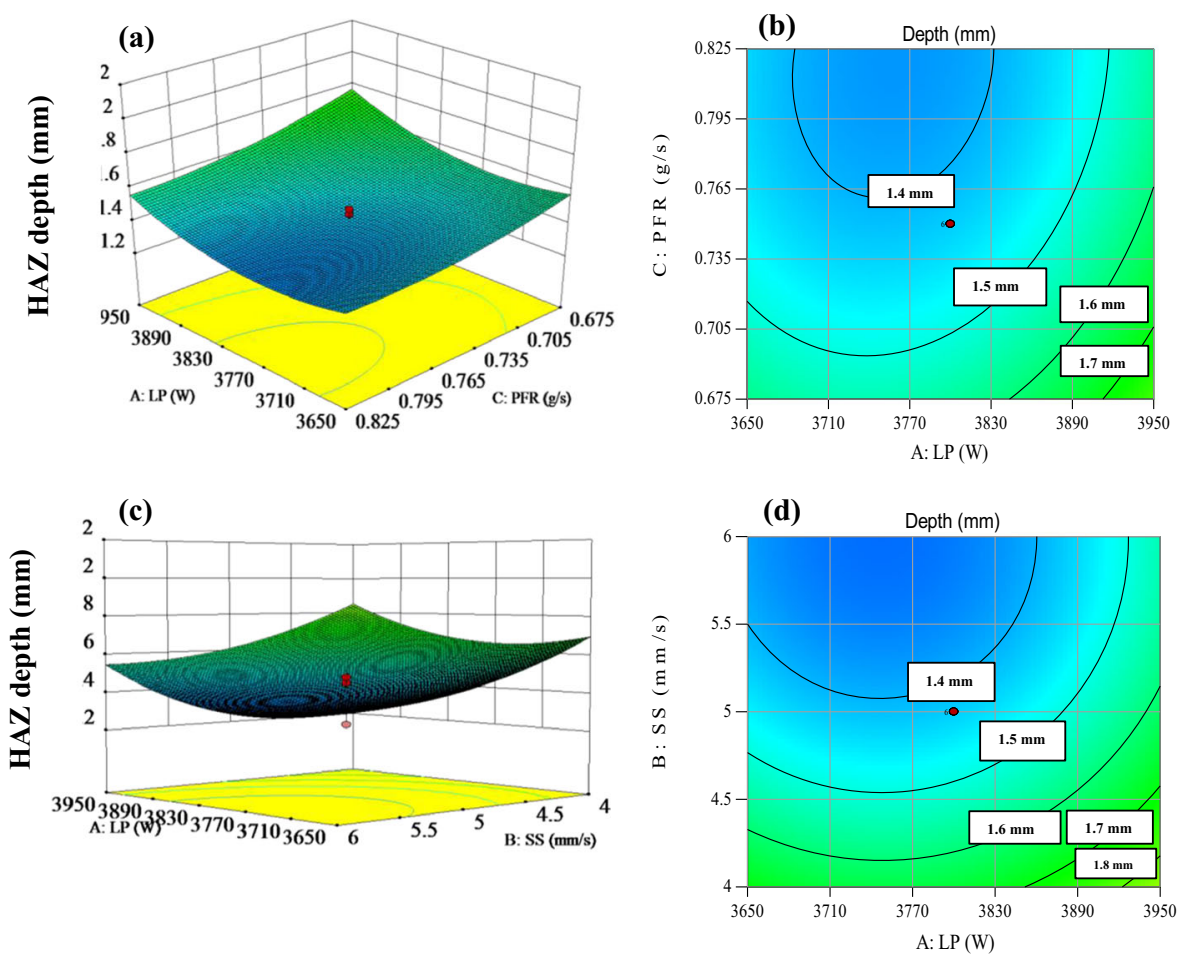

Fig. 9 a 3D surface plot, b counter graph of interaction effect of laser power and powder flow rate on HAZ depth, c 3D surface plot, d contour graph of interaction effect of laser power and scanning speed on HAZ depth 
Perturbation

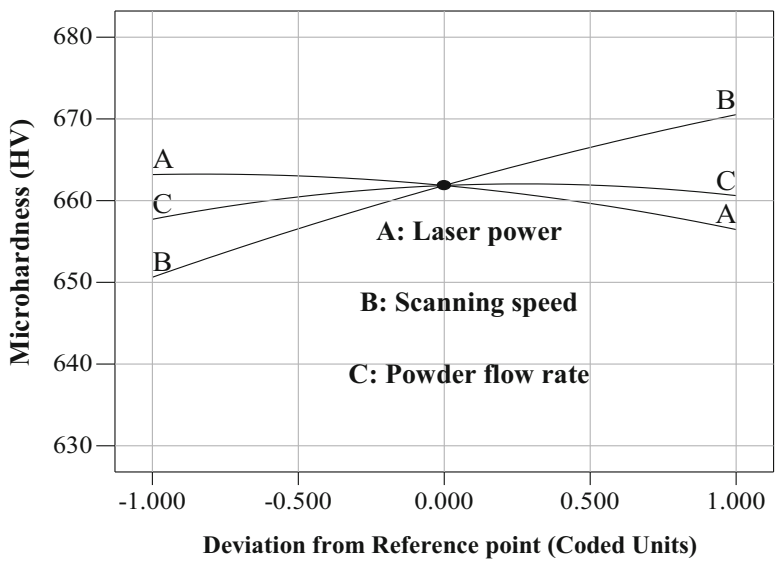

Fig. 10 Perturbation plot showing the effects of all the processing parameters on clad microhardness

a high level, the high coating microhardness could be obtained whether the laser power is high or low. Based on shape of the graphical counters, the maximum hardness was achieved near the boundary of the process parameter domain. Response surfaces and graphical contours of interaction effect of laser power and powder flow rate show that the maximum hardness was obtained close to the center of process domain.
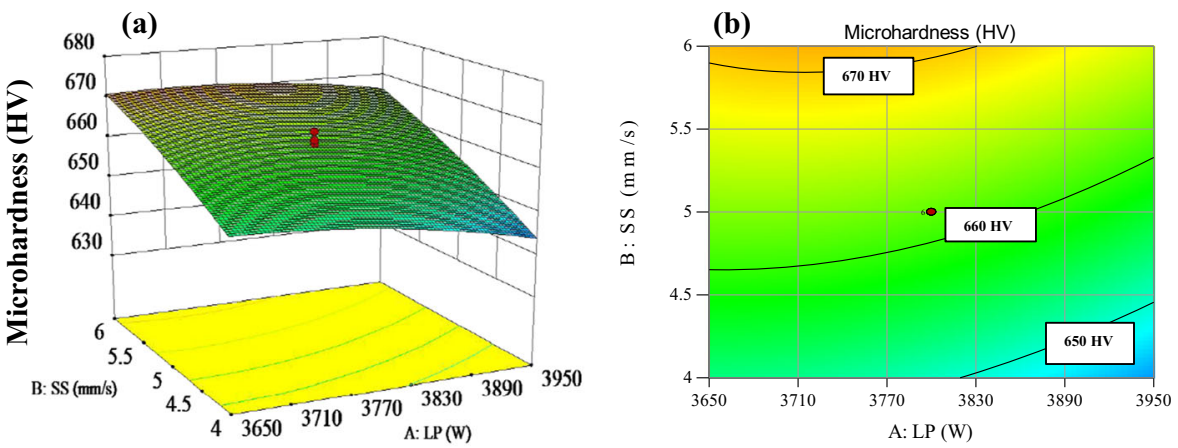

(c)
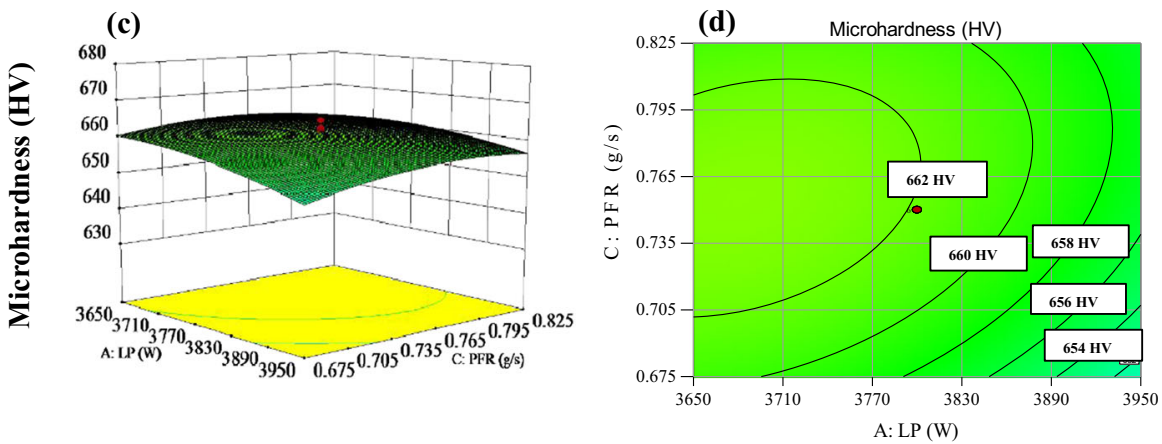

Fig. 11 a 3D surface plot, b counter graph of interaction effects of laser power and scanning speed on clad microhardness, $\mathbf{c} 3 \mathrm{D}$ surface plot, $\mathbf{d}$ contour graph of interaction effect of laser power and powder flow rate on clad microhardness 

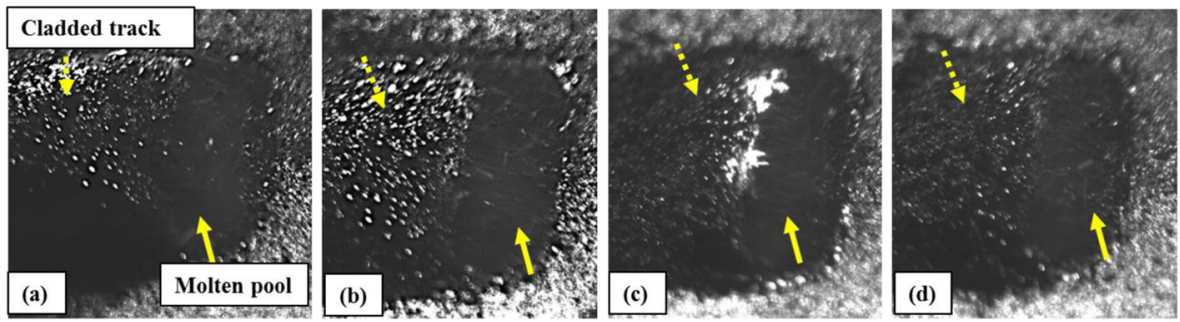

Fig. 12 Images of the molten pool captured by CCD camera a 4100W LP, 5mm/s SS, $0.6 \mathrm{~g} / \mathrm{s}$ PFR, b 3950W LP, $5 \mathrm{~mm} / \mathrm{s} \mathrm{SS}, 0.6 \mathrm{~g} / \mathrm{s}$ PFR, c 3650W, 5mm/s SS, 0.6g/s PFR, d 3500W, 5mm/s, $0.6 \mathrm{~g} / \mathrm{s}$

Figure 11c, d illustrate that by keeping the powder flow rate constant, the microhardness of clad is mainly affected by the laser power. For the high laser power, the microhardness of clad become lower.

In this study, the effect of laser power on the molten pool evolution was captured by high speed CCD camera. The captured images for four different levels of laser power are shown in Fig. 12. In this figure, the laser power decrease from Fig. 12a to d. It is clear with high laser power, the molten pool is brighter and the thickness of cladded track is higher. This figure confirms that by using higher laser power, more input energy is introduced into molten pool, subsequently powder catchment efficiency and clad height increases. In addition, the surface of the cladded track showed that for a lower laser power, the amount of powder not caught by molten pool increased and resulted in unmelted powder sticking to the hot surface of cladded track. The same observation was reported by Liu et al. [20] in laser cladding with high power direct diode laser. This might be attributed to the fact that with lower level of laser power, the amount of input energy was not high enough to melt all of injected powder.

Process Parameter Optimization and Confirmation

For multi-response optimization based on RSM regression models, the desirability function, a function for determining the desired quality of the output responses, was

Table 9 Numerical optimization for central composite design

\begin{tabular}{|c|c|c|c|c|c|c|c|c|}
\hline \multirow[t]{2}{*}{ Exp. } & \multicolumn{3}{|c|}{ Cladding parameters } & \multicolumn{3}{|c|}{ Response value } & \multicolumn{2}{|c|}{ Desirability } \\
\hline & $\begin{array}{l}\mathrm{LP} \\
\text { (W) }\end{array}$ & $\begin{array}{l}\mathrm{SS}(\mathrm{mm} / \\
\mathrm{s})\end{array}$ & $\begin{array}{l}\text { PFR } \\
(\mathrm{g} / \mathrm{s})\end{array}$ & $\begin{array}{l}\text { Height } \\
(\mathrm{mm})\end{array}$ & $\begin{array}{l}\text { HAZ depth } \\
(\mathrm{mm})\end{array}$ & $\begin{array}{l}\text { Microhardness } \\
\text { (HV) }\end{array}$ & & \\
\hline 1 & 3,885 & 6 & 0.825 & 1.24 & 1.23 & 666 & 0.81 & Selected \\
\hline 2 & 3,897 & 6 & 0.825 & 1.25 & 1.26 & 665 & 0.809 & \\
\hline 3 & 3,909 & 6 & 0.825 & 1.27 & 1.29 & 665 & 0.808 & \\
\hline 4 & 3,883 & 6 & 0.825 & 1.24 & 1.23 & 665 & 0.807 & \\
\hline 5 & 3,917 & 6 & 0.825 & 1.28 & 1.32 & 665 & 0.806 & \\
\hline 6 & 3,879 & 6 & 0.825 & 1.22 & 1.23 & 666 & 0.805 & \\
\hline 7 & 3,928 & 6 & 0.824 & 1.33 & 1.38 & 666 & 0.803 & \\
\hline 8 & 3,949 & 6 & 0.822 & 1.32 & 1.43 & 664 & 0.79 & \\
\hline
\end{tabular}




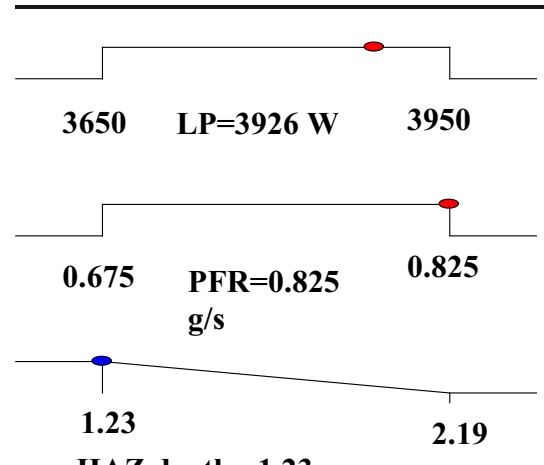

HAZ depth $=1.23 \mathrm{~mm}$

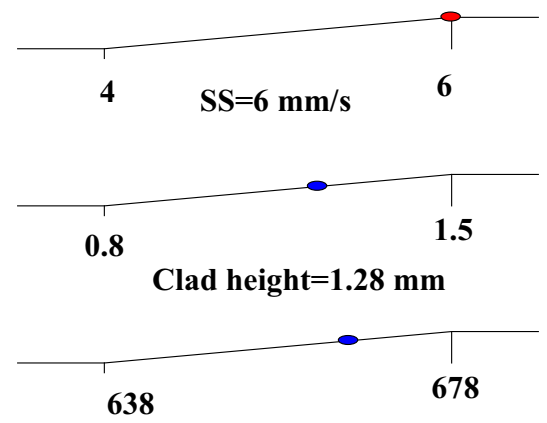

Microhardness $=661 \mathrm{HV}$

\section{Disability $=0.81$}

Fig. 13 Ramps report of multi-objective optimization

used. The desirability approach is found to have advantages of simplicity, flexibility, and allocation of the level of importance for every individual response [17]. In utilizing the desirability method to optimize the process, the nature of the characteristics of the multi response transfers to a single dimensionless factor called quality or desirability factor. This factor is bounded between 0 and 1 . The quality function could be described as: lower-the-better, higher-the-better, and nominal-the-best [21]. The desirability function for multi-response optimization in same time can be expressed as:

$$
\text { Desirability }=\left[\prod_{i=1}^{N} d_{i}^{r i}\right]^{1 / \sum} r i
$$

The desirability function approach is one of the most widely used methods for optimization the multiple responses simultaneously. According to desirability function expressed by Eq. 6, the desirability value combines the optimization criteria into a single value. The desirability function would satisfy all responses with high or low limit of requirements and search for the optimum experimental condition. The ultimate goal in this study is to produce the thickest clad with the lowest HAZ depth and highest microhardness within the selected range of the laser power and powder flow rate, for the maximum scanning speed. The maximum scanning speed was set due to the
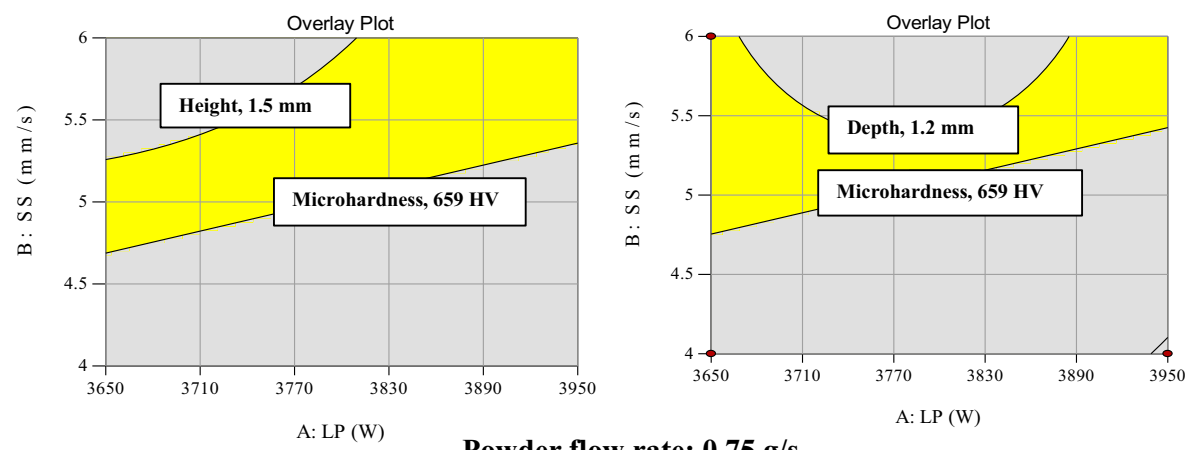

Fig. 14 Overlay contour plot for optimized region 


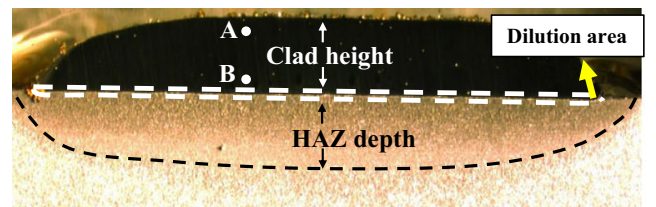

\section{(a)}
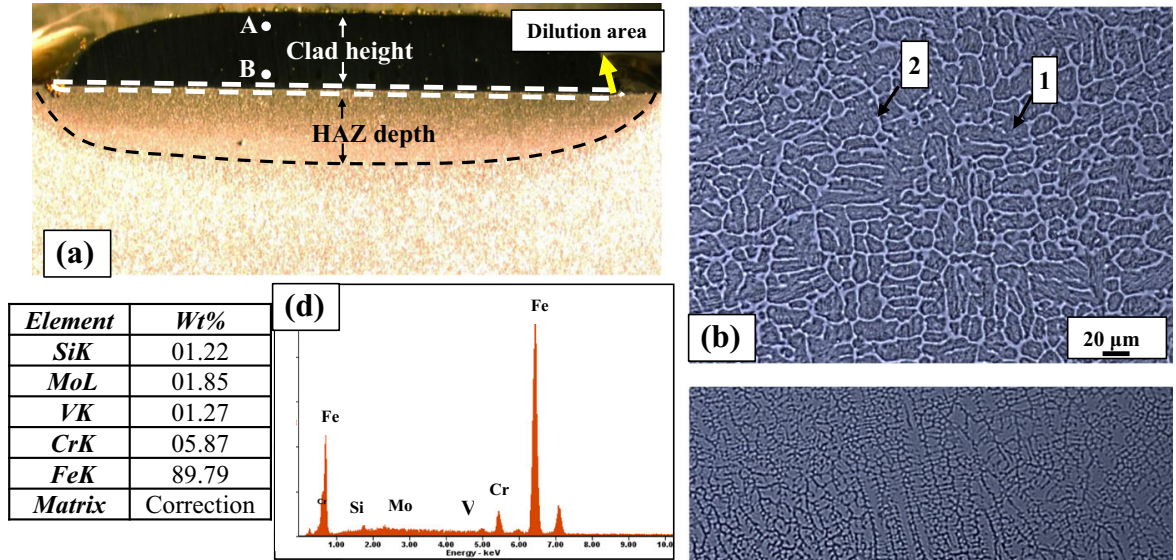

\begin{tabular}{|c|c|}
\hline Element & $\boldsymbol{W t} \%$ \\
\hline SiK & 01.33 \\
\hline MoL & 01.38 \\
\hline $\boldsymbol{V K}$ & 01.09 \\
\hline $\boldsymbol{C r K}$ & 04.70 \\
\hline $\boldsymbol{F e K}$ & 91.50 \\
\hline Matrix & Correction \\
\hline
\end{tabular}
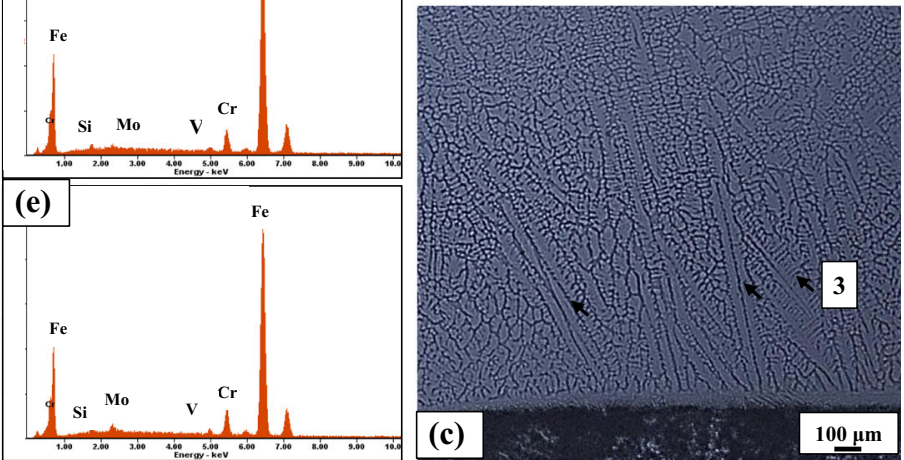

Fig. 15 Optimized AISIH13 cladded track: a cross-sectional view of clad, b micrograph of the microstructure at the top of the clad, $\mathbf{c}$ micrograph of the microstructure at the bottom of the clad, $\mathbf{d}$ EDS analysis at point A, $\mathbf{e}$ EDS analysis at point B

increase in cladding efficiency. The multi-objective optimization results are listed in Table 9 .

The optimal experimental condition with highest desirability value was selected. Figure 13 shows the graphical interpolation of the multi-objective optimization results which is termed as ramp report in Design-Expert software.

The boundaries of optimized region were also determined based on the numerical optimization. The light colored area in Fig. 14 shows the graphical optimized region for clad thicknesses from 1.2 to $1.5 \mathrm{~mm}$, HAZ depth from 1.2 to1.3 mm, and clad hardness from 659 to $666 \mathrm{HV}$.

Finally, the three additional experiments based on the optimal condition were conducted and the averages of measured responses were used for verification. The experimental results of clad thickness, HAZ depth, and microhardness were $1.26 \mathrm{~mm}, 1.24 \mathrm{~mm}$, and $662 \mathrm{HV}$, respectively. Figure 15 shows the cladded track deposited under optimized condition. The clad track had relatively high thickness and shallow HAZ depth. The microstructures of clad at the top and bottom (close to the substrate interface) are shown in Fig. 15b and c, respectively. At top of the clad (marked A) the microstructure consists mainly of fine equiaxed grains including dendrites (marked 1) and interdendrites (marked 2). At the bottom of the clad (marked B) the microstructure mainly consisted of coarse columnar grains (marked 3). Fig. 15d and c shows the EDS analysis of chemical composition at these two regions (A and B) illustrating the uniform chemical composition along the clad thickness. 


\section{Conclusions}

The current study deals with the parametric investigation and application of RSM on process optimization of cladding of high alloy H13 tool steel on mild steel (A36) substrate by HPDDL. Based on the performed analysis, the following conclusions can be drawn:

- The central composite design (CCD) integrated with the response surface methodology (RSM) was a simple, effective, and efficient approach to study the effect of the process parameters on desired outputs and multi-objective optimization .

- The developed analytical models could predict the preferred responses within the relative error of $5 \%$. The desired quality characteristics of the laser clad layer could be achieved by using the optimal process parameters derived from the mathematical models within the process parameter domain.

- Based on RS models, the increase in the scanning speed could decrease the clad height and HAZ depth but increase the clad microhardness. The powder feed rate had a positive effect on the clad height, negative effect on the HAZ depth, and neutral effect on the microhardness. The laser power affected the clad height and HAZ depth positively but had a negative effect on the clad microhardness.

- The graphical optimization determined the boundaries of optimized region which was adequately applied in laser cladding process.

- The modified experimental conditions based on the multi-response optimization method were 3,880 W for laser power, $6 \mathrm{~mm} / \mathrm{s}$ for scanning speed, and $0.825 \mathrm{~g} / \mathrm{s}$ for powder flow rate.

- The obtained clad track under the optimal experimental condition was defect free with uniform chemical composition, high thickness, high microhardness, and relatively shallow HAZ.

In summary, it is very useful to predict the geometry characteristics and mechanical properties of the clad and based on that to select the process parameters. In such way, the fabricated clad could meet the desirable requirements and both raw material and processing time could be correspondingly saved.

Acknowledgment This work was financially supported by NSF's Grant IIP-1,034,562. The authors acknowledge research engineer, Mr. Andrzej Socha at the Research Center for Advanced Manufacturing (RCAM) for his help in conducting the experiments and Roy Beavers for his help in EDS analyses at Southern Methodist University (SMU).

\section{References}

1. De Oliveira, U., Ocelik, V., De Hosson, J.T.M.: “Analysis of coaxial laser cladding processing conditions”. Surface and Coatings Technology 197(2), 127-136 (2005)

2. Beal, V.E., Erasenthiran, P., Hopkinson, N., Dickens, P., Ahrens, C.H.: Optimisation of processing parameters in laser fused $\mathrm{H} 13 / \mathrm{Cu}$ materials using response surface method (RSM)". Journal of materials processing technology 174(1), 145-154 (2006)

3. Toyserkani, E., Khajepour, A., and Corbin, S. F.:"Laser cladding”. CRC press (2010)

4. Steen, W. M.:"Laser surface cladding.” In Laser Surface Treatment of Metals, 369-378. (1986) 
5. Li, L.: The advances and characteristics of high-power diode laser materials processing. Optics and Lasers in Engineering 34(4), 231-253 (2000)

6. Zhu, G., Li, D., Zhang, A., Pi, G., Tang, Y.: The influence of laser and powder defocusing characteristics on the surface quality in laser direct metal deposition". Optics \& Laser Technology 44(2), 349-356 (2012)

7. Fu, Y., Loredo, A., Martin, B., Vannes, A.B..: A theoretical model for laser and powder particles interaction during laser cladding”. Journal of Materials Processing Technology 128(1), 106-112 (2002)

8. Farahmand, P., Kovacevic, R.: An experimental-numerical investigation of heat distribution and stress field in single-and multi-track laser cladding by a high-power direct diode laser. Optics \& Laser Technology 63, 154-168 (2014)

9. Choi, J., Chang, Y.: Characteristics of laser aided direct metal/material deposition process for tool steel". International Journal of Machine Tools and Manufacture 45(4), 597-607 (2005)

10. Farahmand, Parisa, Shuang Liu, Zhe Zhang, and Radovan Kovacevic.:"Laser cladding assisted by induction heating of Ni-WC composite enhanced by nano-WC and $\mathrm{La}<\mathrm{sub}>2</$ sub $>\mathrm{O}<\mathrm{sub}>3<1$ sub>." Ceramics International 40, 15421-15438 (2014)

11. Pinkerton, A.J., Wang, W., Li, L.: Component repair using laser direct metal deposition”. Proceedings of the Institution of Mechanical Engineers, Part B: Journal of Engineering Manufacture 222(7), 827-836 (2008)

12. Syed, W.U.H., Pinkerton, A.J., Li, L.: Combining wire and coaxial powder feeding in laser direct metal deposition for rapid prototyping”. Applied surface science 252(13), 4803-4808 (2006)

13. Balu, P., Leggett, P., Hamid, S., Kovacevic, R.: Multi-Response Optimization of Laser-based Powder Deposition of Multi-track Single Layer Hastelloy C-276”. Materials and Manufacturing Processes 28(2), 173-182 (2013)

14. Mondal, Subrata, Asish Bandyopadhyay, and Pradip Kumar Pal.:"Application of artificial neural network for the prediction of laser cladding process characteristics at Taguchi-based optimized condition." The International Journal of Advanced Manufacturing Technology: 1-8. (2013)

15. Elangovan, S., Anand, K., Prakasan, K.: "Parametric optimization of ultrasonic metal welding using response surface methodology and genetic algorithm.". The International Journal of Advanced Manufacturing Technology 63, 561-572 (2012). no. 5-8

16. Washko, J. F., Parker, H. K., Brookshier, S. W.: US Patent: Powder-delivery apparatus for laser-cladding, US 2012/0199564 A1 (2011)

17. Montgomery, D.C., Montgomery, D.C.: "Design and analysis of experiments"(Vol. 7). Wiley, New York (1984)

18. Acherjee, B., Kuar, A.S., Mitra, S., Misra, D.: A sequentially integrated multi-criteria optimization approach applied to laser transmission weld quality enhancement-a case study. The International Journal of Advanced Manufacturing Technology 65(5-8), 641-650 (2013)

19. Farahmand, Parisa, Prabu Balu, Fanrong Kong, and Radovan Kovacevic.: "Investigation of Thermal Cycle and Hardness Distribution in the Laser Cladding of AISI H13 Tool Steel Produced by a High Power Direct Diode Laser.” In ASME 2013 International Mechanical Engineering Congress and Exposition, pp. V02AT02A078-V02AT02A078. American Society of Mechanical Engineers, (2013)

20. Liu, S., Farahmand, P., Kovacevic, R.: Optical monitoring of high power direct diode laser cladding. Optics \& Laser Technology 64, 363-376 (2014)

21. Sun, Y., Hao, M.: Statistical analysis and optimization of process parameters in Ti6Al4V laser cladding using Nd: YAG laser”. Optics and Lasers in Engineering 50(7), 985-995 (2012) 